\title{
SCREENING AND IMPROVEMENT OF LOCAL ISOLATES OF ASPERGILLUS NIGER FOR CITRIC ACID PRODUCTION
}

\author{
Michael, Macvren Dashen ${ }^{* 1}$, Salleh Alhaji Ado ${ }^{2}$, Joseph Ameh², Tarfena Amapu and \\ Hashimu Zakari ${ }^{1}$ \\ ${ }^{1}$ Department of Microbiology, Faculty of Natural Sciences, University of Jos, P.M.B. 2084, Jos, Nigeria. \\ ${ }^{2}$ Department of Microbiology, Faculty of Science, Ahmadu Bello University, Zaria. \\ Correspondence author: macvrendashen@yahoo.co.uk or dashenm@unijos.edu.ng
}

\section{ABSTRACT}

The study involved the screening of fourteen isolates of Aspergillus niger for citric acid production from glucose. The study was aimed at screening and improving local strains of Aspergillus niger with potential for citric acid production. All the isolates screened produced varying amounts of citric acid, the highest was by the isolate designated CP3 which produced 12.81g/I and the least was B11 and 012 which produced 3.42g/l all after 6 days of submerged fermentation. The isolate CP3 was chosen for further studies. Strain improvement studies which was based on exposure of CP3 to ultraviolet irradiation for 10, 30 and 45 minutes increased citric acid yield to 22.20g/I (48.89\% increase) by mutant M45 followed by a citric acid yield of $16.22 \mathrm{~g} / \mathrm{l}$ by the 30 minutes mutant (M30) and the least being M10 which produced 13.66g/I in all cases after 6 days of fermentation. The mutant (M45) also yielded higher amount of citric acid (19.64g/I) without methanol as additive compared to the parent strain (CP3) which gave a citric acid of 14.94g/I with the addition of methanol after six days (144h) of fermentation in both cases. Finding from this study showed that all the isolates have potential for citric acid production.

Keywords: Isolation, Screening, Improvement, Aspergillus niger, Citric acid

\section{INTRODUCTION}

Citric acid (2-hydroxy-1,2,3-propanetricarboxylic acid) is the most important commercial product, which is found in almost all plant and animal tissues. It exists widely in the nature and is one of the organic acids found in juice of lemon, orange, pineapple, plum, peas, peach and in animal bones, muscles and blood. It has many applications in food, pharmaceutical and cosmetic industries as an acidulant, flavour enhancer, preservative, antioxidant, emulsifier and chelating agent (Ramseh and Kalanselvan, 2011). In 1880, citric acid had been synthesized from glycerol and since that time a number of syntheses from other raw materials have been published. In 1893, Wehmer, discovered that Penicillium spp could produce citric acid from sugar. However, microbial production of citric acid did not become industrially important until World War I disrupted Italian citrus exports.

In 1917, the American food chemist James Curie discovered that certain strains of the mould Aspergillus niger could be efficient citric acid producer, and Pfizer began industrial level production using this microorganism two years later (Wikipedia, 2006).

Citric acid production by fermentation is the most economical and widely used way of obtaining this product. More than $90 \%$ of the citric acid produced in the world is obtained by fermentation. The industrial citric acid fermentation can be carried out in three different ways: submerged fermentation, surface fermentation and solid-state fermentation or Koji process (Madigan et al., 1997).

The improvement of citric acid producing strains had been carried-out using mutagenesis and selection. The most employed technique has been by inducing mutations in parental strains using mutagens. Mutants of Aspergillus niger are used for commercial production of citric acid. Among mutagens used, gamma ( $\mathrm{Y}$ ) radiation, ultraviolet (UV) radiation and chemical mutagens are often used (Soccol et al, 2006). The study was aimed at screening and improving local strains of Aspergillus niger with potential for citric acid production.

\section{MATERIALS AND METHODS}

Isolation and Identification of Aspergillus niger Isolates of Aspergillus niger were obtained from bread, onions, mango, orange pulp, wheat bran and soil. The soil samples were seeded in sterile distilled water, serially diluted and inoculated on Potato Dextrose Agar (PDA).The bread, onions, mango, orange pulp and wheat bran were moistened and kept at room temperature to develop fungal growth which were plated on PDA. Fungal growth suspected to be Aspergillus niger based on macroscopic observation (carbon black or dark brown conidia) were further subcultured on fresh PDA plates. Those that exhibited characteristic $A$. niger growth (initially white, quickly turning black) were subjected to microscopic observation with reference to the manuals of Barnett and Hunter (1972) and Mycology online of Ellis, (2006). For the microscopic identification a drop of lactophenol blue was placed on a clean slide, a bit of the fungal growth was removed and placed inside the drop of lactophenol blue, covered with a cover slip and observed under the microscope using x10 and x40 objective lens. 
Cellulase producing isolates of Aspergillus niger were also obtained from the Microbiology Department of the Ahmadu Bello University, Zaria. All isolates were maintained on Potato Dextrose Agar slants at $4^{\circ} \mathrm{C}$.

\section{Inoculum Preparation and Standardization}

The spores of the isolates were harvested from slant bottles of 6 days old cultures by washing with sterile distilled water containing $0.8 \%$ Tween 80 (Poolyoxyethylene- sorbitanmonooleate) and enumerated using a haemocytometer to give a spore suspension of $10^{7}$ spores /ml (Haq et al., (2003).

\section{Screening of Isolates for Citric Acid Production} Fourteen isolates of Aspergillus niger (CP1, CP2, CP3, CP4, OP5, OP6, S7, S8, M9, B10, B11,O12, O13, WB14) were screened for citric acid production using submerged fermentation in shake flask. The fermentation medium consisted of $150 \mathrm{~g}$ of glucose/litre, $3.1 \mathrm{~g}$ of ammonium nitrate $\left(\mathrm{NH}_{4} \mathrm{NO}_{3}\right) /$ litre, $0.15 \mathrm{~g}$ of potassium in hydrogen phosphate $\left(\mathrm{KH}_{2} \mathrm{PO}_{4}\right) /$ litre and $2.2 \mathrm{~g}$ of magnessium sulphate heptahydrate $\left(\mathrm{MgSO}_{4} .7 \mathrm{H}_{2} \mathrm{O}\right) /$ litre. The $\mathrm{pH}$ of the medium was adjusted to 6.0 with $1 \mathrm{M}$ sodium hydroxide $(\mathrm{NaOH})$ using $\mathrm{pH}$ metre (HANNA HI 991000). Fermentation was carried out at temperature of between $26^{\circ} \mathrm{C}-29.5^{\circ} \mathrm{C}$ on an orbital shaker at a speed of 450rpm and length of fermentation of $168 \mathrm{~h}$ (7days). Throughout the work the fermentations were carried-out in $500 \mathrm{ml}$ Erlenmeyer flasks and the working volume was $60 \%(300 \mathrm{ml})$ of the flask capacity. The inoculum size was $10 \mathrm{ml}$ of the spores suspension corresponding to $10^{7}$ spores per $\mathrm{ml}$ (AlDelaimy and El-Holi, 2003).

\section{Analytical Methods}

Citric acid was determined daily by filtering $10 \mathrm{ml}$ of the culture medium through Whatman filter paper no. 41. Two to three drops of phenolphthalein as indicator was added and the filtrate was titrated against $0.1 \mathrm{M}$ $\mathrm{NaOH}$ and calculated as \% citric acid according to the following formula (Al- Delaimy and El-Holi, 2003):

$$
\begin{aligned}
& \% \text { Citric acid }=\frac{192.13 \times \mathrm{M}_{\mathrm{NaOH}} \times \mathrm{V}_{\mathrm{NaOH}}}{\text { Weight of substrate }} \\
& \text { Where, }
\end{aligned}
$$

192.13 = molar mass of citric acid.

$\mathrm{M}_{\mathrm{NaOH}}=$ molarity of $\mathrm{NaOH}$

$\mathrm{V}_{\mathrm{NaOH}}=$ volume of $\mathrm{NaOH}$ consumed during titration .

Dry mycelia weight was determined as described by $\mathrm{Al}$ - Delaimy and El-Holi, (2003), Haq et al., (2003).

Residual sugar was determined from the filtrate obtained above using the $3,5-$ Dinitrosalycilic acid (DNS) method (Haq et al., 2003).

\section{Preliminary Strain Improvement Studies}

The spore of the wild Aspergillus niger isolate (CP3) was subjected to $254 \mathrm{~nm}$ (short wavelength) of ultraviolet (UV) irradiation for 10, 30 and 45minutes using Phillips germicidal lamp and tested for citric acid production from glucose.

\section{UV Irradiation Procedure}

The UV irradiation was carried-out using a modification of the method of Kubicek et al, 1986. Five millilitres of sterile distilled water containing $0.1 \%(\mathrm{w} / \mathrm{v})$ Tween 80 was pipetted into three slant bottles of 7 day old cultures of the wild Aspergillus niger isolate and shaken vigorously to break clumps. This was further diluted to give a final density of $2 \mathrm{x}$ $10^{6}$ spores per $\mathrm{ml}$. Ten millilitres of the suspension were pipetted into three different Petri dishes (13.8 $\mathrm{cm}$ diameter). The three dishes labelled 10, 30 and 45 minutes were placed separately inside the dispensing cabinet $20 \mathrm{~cm}$ away from the centre of the germicidal UV lamp source for the period corresponding to the minutes on their labels. The Petri dishes were covered with alluminium foil for one hour and used for the isolation of potential mutants.

\section{Presumptive Mutant Isolation}

This was also based on the method of Kubicek et al, 1986. Their identification was based on the assumption that mutants lacking citrate control of phosphofructokinase would grow faster on a sucrose medium containing citrate. The diluted mutagenized spore suspensions were plated on solid medium containing $20 \%(\mathrm{w} / \mathrm{v})$ sucrose and $5 \%(\mathrm{w} / \mathrm{v})$ citrate as carbon sources. Other inorganic nutrients and nitrogen source were essentially as used in the citric acid fermentation medium except that the $\mathrm{pH}$ was adjusted to 3.5 with $1 \mathrm{M} \mathrm{HCl}$.

The fastest-growing colonies were considered to be less affected in carbohydrate breakdown by citrate and thus selected for further work.

\section{Screening of Mutants for Citric Acid Production}

The selected mutants exposed to UV irradiation for 10 , 30 , and 45 minutes were screened for citric acid production using $15 \%$ glucose. Other nutrients include $0.15 \mathrm{~g}$ of $\mathrm{KH}_{2} \mathrm{PO}_{4} /$ litre, $2.2 \mathrm{~g}$ of $\mathrm{MgSO}_{4} .7 \mathrm{H}_{2} \mathrm{O} /$ litre, $3.1 \mathrm{~g}$ of $\mathrm{NH}_{4} \mathrm{NO}_{3} /$ litre, $3 \%(\mathrm{v} / \mathrm{v})$ methanol. The $\mathrm{pH}$ used was 5.5, agitation rate was 450rpm and length of fermentation was 7 days. These conditions were based on findings of an earlier optimization of cultural conditions studies by the authors of this paper.

\section{Statistical Analysis}

Analysis of variance (ANOVA) was carried out to determine the difference in the mean citric acid yield between the three mutants (M45, M30, M10).

\section{RESULTS}

\section{Screening Tests}

Table 1 shows the results obtained during the screening of fourteen isolates of Aspergillus niger for citric acid production. All the isolates screened produced varying amounts of citric acid, the highest being CP3 which produced $12.81 \mathrm{~g} / \mathrm{l}$ and the least was B11 and 012 which produced $3.42 \mathrm{~g} / \mathrm{l}$ both after 6 days of fermentation. All the other isolates produce the highest amount of citric acid after six days of fermentation except OP5, OP6, M9, B11 and O13 which yielded the highest amount of citric acid after $120 \mathrm{~h}$ (five days) of fermentation. 
There was a progressive decrease in residual sugar concentration, the least being that of CP3 $(2.50 \mathrm{~g} / \mathrm{l})$ and the highest being that of $012(30.85 \mathrm{~g} / \mathrm{l})$ both after $168 \mathrm{~h}$ (seven days) of fermentation. Mycelia weight increased steadily for all the isolates with the highest values obtained after seven days of fermentation.

\section{Preliminary Strain Improvement Studies}

Figures 1, 2 and 3 represent citric acid yield, residual sugar concentration and mycelia weight of $A$. niger (CP3) after exposure to ultraviolet irradiation for 10, 30 and 45 minutes respectively. The mutant (M45) obtained after exposure of parent $A$. niger to 45 minutes of ultraviolet radiation gave the highest citric acid yield $(22.20 \mathrm{~g} / \mathrm{l})$ after $144 \mathrm{~h}$ of fermentation followed by a citric acid yield of $16.22 \mathrm{~g} / \mathrm{l}$ by the 30 minutes mutant (M30). The mutant obtained from 10 minutes (M10) exposure to ultraviolet irradiation produced the least amount of citric acid (13.66g/l). There was no significant difference in mean citric acid yield between the M45 and M30 and also between M30 and M10 ( $P \geq 0.05)$, but there was significant difference in mean citric acid yield between M45 and M10 ( $P \leq 0.05)$. In all cases, the concentration of residual sugar steadily declined throughout the seven days of fermentation, from $124.50 \mathrm{~g} / \mathrm{l}$ to $4.70 \mathrm{~g} / \mathrm{l}$, $126.00 \mathrm{~g} / \mathrm{l}$ to $10.80 \mathrm{~g} / \mathrm{l}$ and $118.55 \mathrm{~g} / \mathrm{l}$ to $2.20 \mathrm{~g} / \mathrm{l}$ after exposure to ultraviolet irradiation for 10,30 and 45 minutes respectively while mycelia weight increased throughout the seven days of fermentation, from $2.99 \mathrm{~g} / \mathrm{l}$ to $12.58 \mathrm{~g} / \mathrm{l}, 3.44 \mathrm{~g} / \mathrm{l}$ to $11.44 \mathrm{~g} / \mathrm{l}$ and $3.01 \mathrm{~g} / \mathrm{l}$ to $12.48 \mathrm{~g} / \mathrm{l}$ after exposure to ultraviolet irradiation for 10,30 and 45 minutes respectively.

Figure 4 shows comparison of citric acid yield between parent and mutant $A$. niger (CP3) with and without methanol as additive. The mutant yielded higher amount of citric acid $19.64 \mathrm{~g} / \mathrm{l}$ without methanol and $22.20 \mathrm{~g} / \mathrm{l}$ with methanol compared to the parents $(14.09 \mathrm{~g} / \mathrm{l}$ from parent without methanol and $14.94 \mathrm{~g} / \mathrm{l}$ from parent with methanol) after six days (144h) of fermentation. Residual sugar concentration decreased all through the fermentation period, from $109.90 \mathrm{~g} / \mathrm{l}$ to $2.85 \mathrm{~g} / \mathrm{l}, 122.60 \mathrm{~g} / \mathrm{l}$ to $15.90 \mathrm{~g} / \mathrm{l}, 127.80 \mathrm{~g} / \mathrm{l}$ to 2.60 and 118.50 to $2.20 \mathrm{~g} / \mathrm{l}$ from parent without methanol, parent with methanol, mutant without methanol and mutant with methanol respectively while mycelia weight increased steadily up to day seventh of the fermentation, the highest value obtained being $12.48 \mathrm{~g} / \mathrm{l}$ from mutant with methanol.

Table 1: Citric acid yield $(\mathrm{g} / \mathrm{l})$, residual sugar concentration $(\mathrm{g} / \mathrm{l})$ and mycelial weight $(\mathrm{g} / \mathrm{l})$ of fourteen isolates of $\boldsymbol{A}$. niger during the screening tests

\begin{tabular}{|c|c|c|c|c|c|c|c|}
\hline \multirow[t]{2}{*}{ Isolates } & \multicolumn{7}{|c|}{ Days } \\
\hline & 1 & 2 & 3 & 4 & 5 & 6 & 7 \\
\hline \multicolumn{8}{|l|}{ CP1 } \\
\hline CAY & 8.11 & 8.54 & 8.96 & 9.39 & 9.39 & 9.82 & 7.69 \\
\hline RSC & 125.65 & 108.55 & 86.20 & 62.70 & 34.55 & 17.46 & 6.50 \\
\hline MW & 3.11 & 4.50 & 7.01 & 10.15 & 13.67 & 14.03 & 16.60 \\
\hline \multicolumn{8}{|l|}{$\mathrm{CP} 2$} \\
\hline CAY & 5.98 & 8.54 & 9.39 & 9.39 & 10.25 & 10.67 & 8.54 \\
\hline RSC & 132.00 & 106.40 & 87.60 & 60.50 & 45.55 & 20.50 & 4.65 \\
\hline MW & 2.80 & 4.52 & 6.80 & 9.95 & 11.05 & 15.00 & 16.95 \\
\hline \multicolumn{8}{|l|}{ CP3 } \\
\hline CAY & 7.26 & 10.25 & 11.10 & 11.95 & 12.38 & 12.81 & 11.53 \\
\hline RSC & 124.50 & 98.95 & 76.70 & 52.86 & 28.10 & 10.50 & 2.50 \\
\hline MW & 3.05 & 4.45 & 6.80 & 9.00 & 11.00 & 13.05 & 15.05 \\
\hline \multicolumn{8}{|l|}{ CP4 } \\
\hline CAY & 6.40 & 10.25 & 10.25 & 11.10 & 11.53 & 11.95 & 10.67 \\
\hline RSC & 124.40 & 98.70 & $78 . .25$ & 50.50 & 32.50 & 18.70 & 7.00 \\
\hline MW & 3.79 & 4.65 & 5.98 & 7.56 & 10.77 & 12.09 & 14.97 \\
\hline \multicolumn{8}{|l|}{ OP5 } \\
\hline CAY & 6.40 & 6.83 & 8.54 & 9.82 & 10.67 & 10.67 & 8.54 \\
\hline RSC & 130.80 & 117.15 & 98.35 & 78.70 & 62.70 & 45.60 & 15.05 \\
\hline $\begin{array}{l}\text { MW } \\
\text { OP6 }\end{array}$ & 4.98 & 7.00 & 8.50 & 11.40 & 14.11 & 16.75 & 19.00 \\
\hline CAY & 4.70 & 4.70 & 5.12 & 6.40 & 7.69 & 7.26 & 6.40 \\
\hline RSC & 131.20 & 112.40 & 99.60 & 80.40 & 57.35 & 39.10 & 19.90 \\
\hline MW & 4.50 & 6.14 & 8.00 & 11.68 & 16.77 & 19.01 & 20.00 \\
\hline \multicolumn{8}{|l|}{ S7 } \\
\hline CAY & 2.99 & 5.12 & 5.12 & 5.55 & 6.40 & 7.26 & 6.40 \\
\hline RSC & 135.05 & 112.00 & 91.53 & 72.10 & 49.70 & 27.92 & 7.44 \\
\hline MW & 3.05 & 6.05 & 8.64 & 11.87 & 15.11 & 18.00 & 21.90 \\
\hline S8 & & & & & & & \\
\hline CAY & 4.70 & 5.98 & 6.40 & 6.83 & 8.11 & 9.39 & 7.69 \\
\hline RSC & 124.15 & 109.50 & 80.70 & 60.20 & 39.93 & 20.00 & 8.55 \\
\hline
\end{tabular}


Bajopas Volume 6 Number 1 June, 2013

Table 1 Continue

\begin{tabular}{|c|c|c|c|c|c|c|c|}
\hline \multicolumn{4}{|l|}{ Isolates } & \multicolumn{4}{|l|}{ Days } \\
\hline & 1 & 2 & 3 & 4 & 5 & 6 & 7 \\
\hline MW & 3.54 & 4.50 & 6.50 & 9.12 & 12.22 & 15.60 & 17.00 \\
\hline M9 & & & & & & & \\
\hline CAY & 4.70 & 5.55 & 6.40 & 7.69 & 9.82 & 8.97 & 7.26 \\
\hline RSC & 126.50 & 109.85 & 90.65 & 71.42 & 37.05 & 19.00 & 8.22 \\
\hline $\begin{array}{l}\text { MW } \\
\text { B1O }\end{array}$ & 4.06 & 6.55 & 8.98 & 10.23 & 11.09 & 12.11 & 13.55 \\
\hline CAY & 2.56 & 4.27 & 5.98 & 5.98 & 7.26 & 8.11 & 7.69 \\
\hline RSC & 134.65 & 111.45 & 90.45 & 60.50 & 43.85 & 31.70 & 16.34 \\
\hline $\begin{array}{l}\text { MW } \\
\text { B11 }\end{array}$ & 3.11 & 4.88 & 6.00 & 7.90 & 9.89 & 11.77 & 13.57 \\
\hline CAY & 3.42 & 3.42 & 5.55 & 6.40 & 7.26 & 3.42 & 2.56 \\
\hline RSC & 131.20 & 119.25 & 97.00 & 81.00 & 62.85 & 49.10 & 20.50 \\
\hline $\begin{array}{l}\text { MW } \\
\text { O12 }\end{array}$ & 5.00 & 8.20 & 9.14 & 12.55 & 16.00 & 19.02 & 19.50 \\
\hline CAY & 2.56 & 2.56 & 2.56 & 2.99 & 2.99 & 3.42 & 2.56 \\
\hline RSC & 137.20 & 124.90 & 114.65 & 90.50 & 75.05 & 48.88 & 30.85 \\
\hline $\begin{array}{l}\text { MW } \\
\text { O13 }\end{array}$ & 2.22 & 4.44 & 6.01 & 8.08 & 11.11 & 13.78 & 14.84 \\
\hline CAY & 4.27 & 4.70 & 6.83 & 7.69 & 9.39 & 8.11 & 8.11 \\
\hline RSC & 132.90 & 118.85 & 101.75 & 82.50 & 54.35 & 30.80 & 15.45 \\
\hline MW & 2.90 & 3.74 & 4.44 & 7.07 & 9.03 & 10.91 & 11.06 \\
\hline WB14 & & & & & & & \\
\hline CAY & 4.70 & 6.40 & 6.83 & 7.69 & 8.11 & 8.54 & 7.69 \\
\hline RSC & 131.10 & 102.30 & 78.40 & 50.50 & 38.65 & 25.80 & 10.00 \\
\hline MW & 3.50 & 5.03 & 5.94 & 7.07 & 9.77 & 11.11 & 13.99 \\
\hline
\end{tabular}

Key: $\mathrm{CAY}=$ Citric acid yield, RSC = Residual sugar concentration, MW = Mycelial weight.

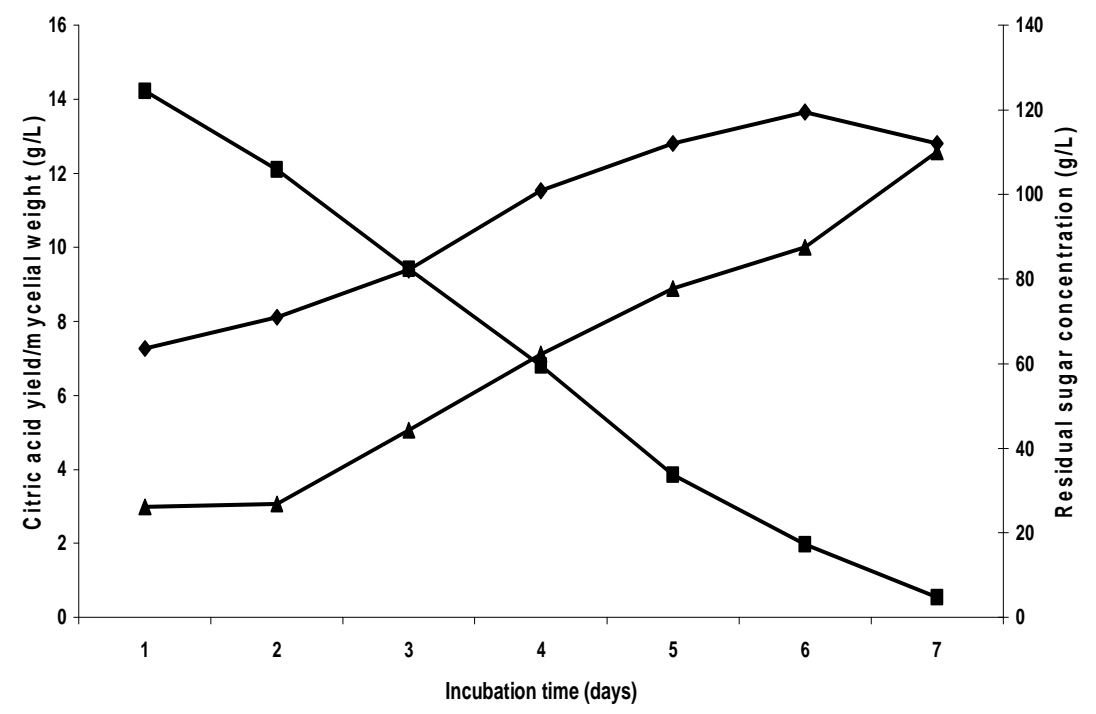




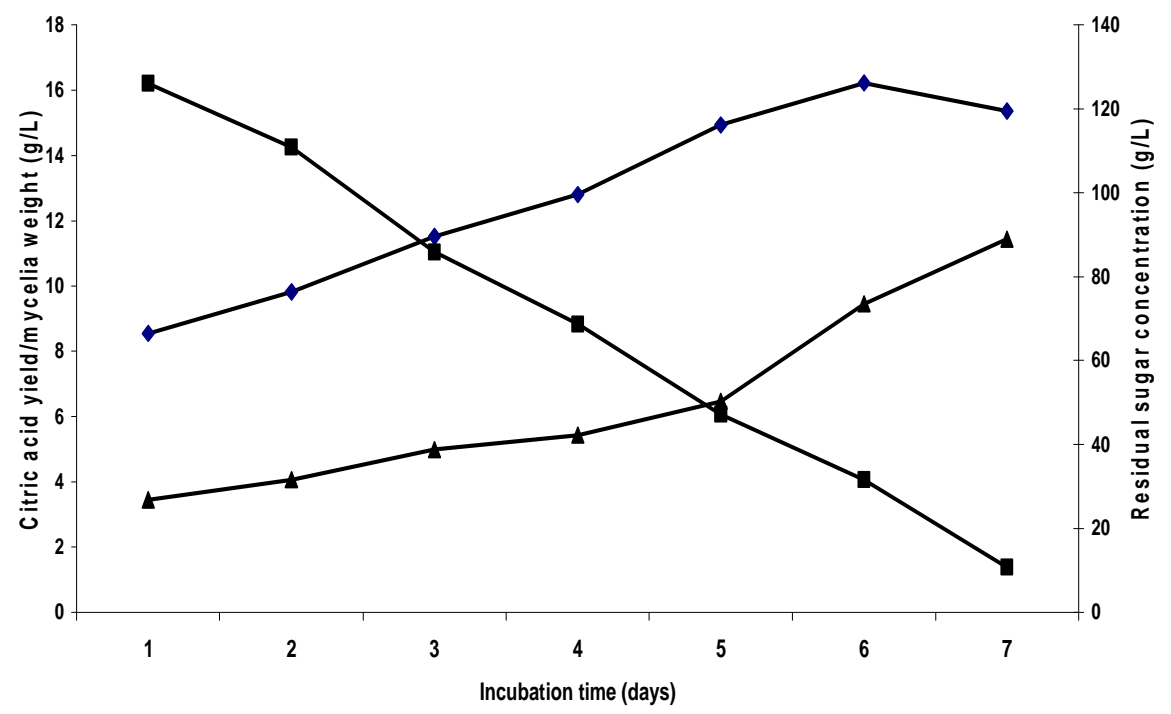

$\checkmark$ Citric acid yield

Figure 2: Citric acid yield, residual sugar concentration and mycelia weight of $A$. niger at 30 minutes exposure to UV radiation

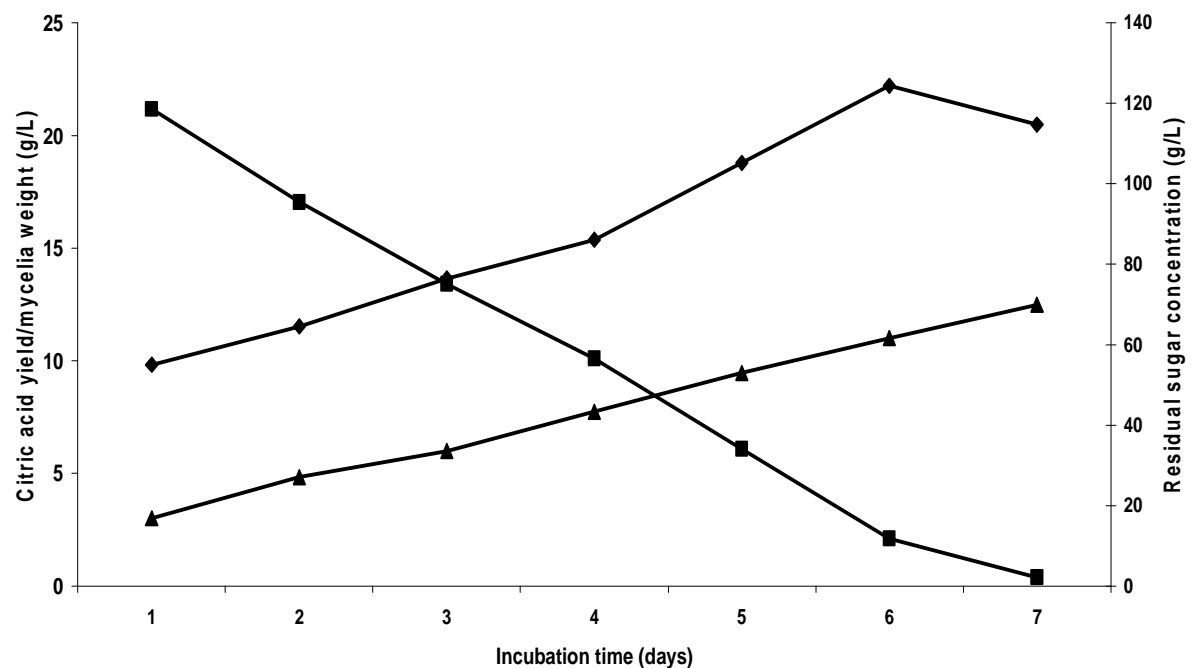

Figure 3: Citric acid yield, residual sugar concentration and mycelia weight of $A$. niger at 45 minutes exposure to UV radiation 


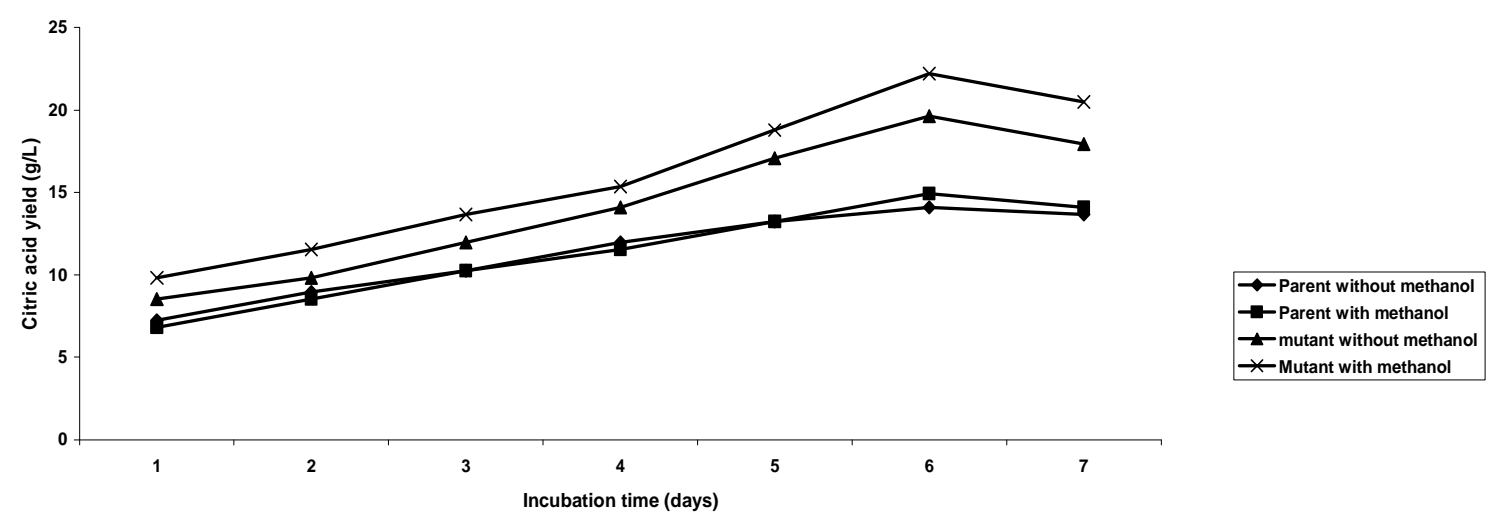

Figure 4: Comparism of Citric acid yield between parent and mutant $A$. niger with and without methanol as additive

\section{DISCUSSION}

Screening of Aspergillus niger Isolates for Citric Acid Production

Fourteen isolates of Aspergillus niger code named CP1- 4 (Cellulase producing), OP5 and OP6 (from orange pulp), S7 and S8 (from soil), M9 (from mango), B10 and B11 (from bread), 012 and 013 (from onions) and WB14 (from wheat bran) were screened for citric acid production. Of these isolates, CP3 produced the highest amount of citric acid $(12.81 \mathrm{~g} / \mathrm{l})$ after six days. The citric acid yield was much lower than those of the 12 isolates of Aspergillus niger studied by Ali et al, 2002 in which the best isolate $A$. niger GCBT7 produced $84.95 \mathrm{~g} / \mathrm{l}$ citric acid. The low yield obtained from the isolates studied in this work compared to those studied by Ali et al., 2002 may be due to differences in carbon source (glucose was used in this work while molasses was used by Ali et al., 2002), molasses consists predominantly of sucrose, the low yield may also be due to difference in strain of the $A$. niger used in both studies. Variation in temperature may have also contributed to the low yield obtained in this study, the shaker used in this study did not have temperature control mechanism, and fermentation was therefore based on ambient temperature which was between $26^{\circ} \mathrm{C}-29.5^{\circ} \mathrm{C}$ during the studies. Ali et al., 2002 used a constant temperature of $30^{\circ} \mathrm{C}$.

\section{Preliminary Strain Improvement Studies}

Highest citric acid yield $(22.20 \mathrm{~g} / \mathrm{l})$ was obtained from the 45 minutes mutants (M45) after 6 days of

\section{REFERENCES}

Abdullah-Al-Mahin, A., Sharifuzzaman, B. M., Faruk, M. O., Kader, M.A. Alam, J. Begum, R. and Harun-Or-Rashid, R. (2012). Improved Citric Acid Production by Radiation Mutant fermentation. The $A$. niger isolates exposed to ultraviolet radiation for 10 minutes yielded less citric acid $(13.66 \mathrm{~g} / \mathrm{l})$ compared to the parent $(14.95 \mathrm{~g} / \mathrm{l})$ after $144 \mathrm{~h}$ (six days) of fermentation. This may be because exposure of the parent $A$. niger (CP3) to ultraviolet irradiation for ten minutes was too short to have caused any positive mutation.

The 45 minutes mutant (M45) gave 1.49 fold increase in citric acid yield while the 30 minutes mutant (M30) gave 1.08 fold increase in citric acid yield compared to the parent strain (CP3). The higher citric acid yield by these mutants may be because phosphofructokinase regarded as a key regulatory enzyme for citric acid formation is able to overcome feedback inhibition by citrate (Ward et al., 2006). The yield obtained in this study by all the three mutants was much higher than the yield of $12.81 \mathrm{~g} / \mathrm{l}$ reported by Abdullah-Al-Mahin et al. (2012). Several workers in this field reported higher citric acid yield from mutant A. niger than the parent strain. (Ledezma et al., 1970; Haq et al., 2002; Zhang et al., 2002; Ikram-Ul et al., 2003; Marin et al. 2003; Iqbal et al., 2004).

\section{CONCLUSION}

The results of the isolation and screening tests showed that all the $A$. niger isolates studied have the potential for citric acid production. Citric acid productivity further increased after strain improvement studies. The mutant (M45) obtained was also able to produce more citric acid without methanol as additive than the parent (CP3) strain with methanol.

Aspergillus niger Using Sugarcane Bagasse Extract. Biotechnology, 11: 44-49.

Al-Delamy, K. S. and M. El-Holi, (2003). Citric acid production from whey sugars and additives by A.niger. African Journal of Biotechnology, 2:10: $356-359$. 
Ali, S., Ikram, H. Quadeer, M.A. and Iqbal, J. (2002). Production of citric acid by $A$. niger using cane molasses in a stirred fermentor. Elec. Journal of Biotechnology, $5: 3: 1-7$.

Barnett, H. L. and Hunter, B. B. (1972). Illustrated Genera of Imperfect fungi. Burgess Publishing Company, Minneapolis. pp 62 63.

Ellis, D. (2006). Mycology online. The University of Adelaide, Australia.

Haq, I. U., Ali, S. Qadeer, M. A. and Iqbal, J. (2003). Stimulatory effect of alcohols (methanol and ethanol) on citric acid production by a 2 deoxy $\mathrm{D}$ - glucose resistant culture of $A$. niger BCB - 47. Bio. Technol., 86 :3: 227228.

Ikram-Ul, H., Ali, S. Qadeer, M. A. and Iqbal, J. (2002). Citric acid fermentation by a mutant strain of $A$. niger GCMC-7 using molasses based medium. Elec. J. of Biotechnology, 5: 2: 6-9.

Ikram-Ul, H., Ali, S. Qudeer, M.A. and Iqbal, J. (2003). The kinetic basis of the role of $\mathrm{Ca}^{++}$for higher yield of citric acid in a repeated batch cultivation system. World Journal of Microbiology and Biotechnology,19:817 823.

Iqbal, J. S. Ali, M. A. Qadeer, and Ikram-UI, H. (2004). Citric acid production by selected mutants of A.niger from cane molasses. Electricity Journal of Biotechnol., 93: (2) :125-130.

Kubicek, P.C., Rohr, V and Schreferl, G. (1986). Inhibition of citric acid accumulation by manganese ions in $A$. niger mutants with reduced citrate control of phosphofructokinase. Journal of Biotechnology, 165: 3: 1019 - 1022.

Madigan, M., Martinko, T. and Parker, J. M., (1997). Biology of microorganisms. Prentix Hall Inc. pp 181-188.

Marin, J. M. Conte, F., and Ana, P. (2003). Selection of 5-fluorocytosine-resistant mutants from an $A$. niger citric acid producing strain. Brazilian Journal of Microbiology, 34: 1: 1-7.

Ramseh, T. and Kalanselvan, M. (2011). An Experimental Study on Citric Acid Production by Aspergillus niger Using Gelidiella acerosa as a Substrate. Indian Journal of Microbiology, 51(3): 289-293.

Soccol, C. R., Vandenberghe, L. P. S., Rodrigues, C. and Pandey, A. (2006). New perspectives for citric acid production and application. Food Technology Biotechnology, 44: 2: 141-149.

Ward, O. P., J. Qin, J. Y. Dhanjoon and Singh, A. (2006). Physiology and biotechnology of Apergillus. Advance in Applied Microbiology, 58:1-10.

Wikipedia (2006). http://en.wikipedia.org/wiki/citric Wikimedia Foundation, Inc.

Zhang, H. X., Zhuang, X. L., Yang, J. Z. and Qi, H. Y. (2002). Preparation of levoglucosan by pyrolysis of cellulose and its citric acid fermentation. Bioresource Technology,79:6366. 